\title{
Correlations of Socio-economic Backgrounds and Flood Preventive Behavioral Attitudes for Taipei
}

\author{
Yung-Jaan Lee ${ }^{1, *}$, Shih-Ying Lin ${ }^{1}$ \\ ${ }^{1}$ Chung-Hua Institution for Economic Research, Division of Taiwan Economy, 110 Taipei, Taiwan
}

\begin{abstract}
Under the impact of climate change, the world is facing various extreme weather challenges. Cities face higher frequency and severity of these challenges due to high population density and high levels of business and commerce activities. How to reduce disaster risk has become an important connotation of risk city governance. People's attitudes toward disaster prevention can help reduce disaster risk and management efforts and reduce mortality and economic losses. Using a stratified random sampling method, this study selected 600 respondents from four different environmentally sensitive districts in Taipei to examine the relationships between their socio-economic backgrounds (age and residence duration) and flood preventive behavioral attitudes. The analyses of the Chi-squared test indicate that there is a high correlation between residents' age and flood preventive behavioral attitudes, while a low correlation in different regions. There are moderate to low correlations between the prevention behavioral attitudes and age of the residents in Zhongshan and Wenshan districts with low natural vulnerability / low social vulnerability. The relationship between residence duration and flood prevention behavioral attitudes was only associated in districts with high natural vulnerability / high social vulnerability, while the respondents in other districts did not show correlation relationships. It is recommended to increase the residents' flood prevention behavioral attitudes to encourage positive behavior in the reduction of flood risk in different areas and similar environments.
\end{abstract}

\section{Introduction}

The climate change phenomenon points to the potential for significant changes in earth's surface temperature over the next 50 years. Therefore, politically, global economies, societies and ethics must respond to climate change to come out with policy leadership and environmental education responses. [1] According to Global Climate Risk Index 2020 [2], the first-ranked country due to disasters or risks caused by climate change from 1998 to 2018 was Puerto Rico, with Taiwan ranked 41st. Taiwan ranked 75th in the world in 2018 with disasters or risks from climate change (compared to 7th in 2016 and 90th in 2017; [3-4]). According to the 2016-2018 ranking data, the three-year risk index gap changed so dramatically, indicating the unpredictability of disasters and emphasizing the importance of responding to climate change risks.

On the other hand, by the end of the 20th century, the greenhouse effect in urban areas was more significant than in rural areas. The climate changed considerably over the same period, while urban-related water issues raised concerns in the global scientific community. The overuse of "grey construction", such as concrete and asphalt in urban development, results in impermeable surfaces that could not absorb water [5]. Studies also found that urban flooding caused by river overflows, flash floods and drainage problems was the most affected natural disaster in the number of people affected and economic losses [6]. Of these, floods account for about one-third of global natural disasters and one-third of economic losses in all natural disasters, considered to be the most influential disaster [7] and the incident with the highest direct impact on humans [6]. Previous studies have shown that floods are highly associated with climate change among environmental risks [8-9].

Taiwan is a subtropical island state with a dramatic change in its climate risk index over the years. Taipei, one of the six municipalities in Taiwan, ranked 4th in the Lloyd's City Risk Index, with the main threat being tropical windstorm, causing a $\$ 12.88$-billion risk of loss [10]. The characteristics of Taipei's natural vulnerability are mainly potential flooded areas. In view of the depth of flooding, the most vulnerable areas include Zhongshan District and Neihu District. Although Zhongshan District has less slope-related disasters, when the daily rainfall of more than $600 \mathrm{~mm}$, the flood depth of more than one meter accounts for $15.13 \%$ of the whole areas [11]. In addition, according to the statistics of the Taipei City Fire Department and the District Offices in 2014, floods were significant disasters in all 12 districts. Restated, potential flooding, reconstruction after floods, landslides after floods, etc. will occur in 12 districts in Taipei.

International organizations and governments around the world are paying more attention to the impact of

\footnotetext{
* Corresponding author: yungjaanlee@gmail.com
} 
climate change. Taiwan is environmentally sensitive due to the geographical constraints of the island nations. Taipei is densely populated and affected by social vulnerability and high ecological footprint=[13] (Lee, 2019). Hence, a severe disaster may lead to high economic losses and losses of life. Furthermore, Taipei's high-density land use patterns increase the impermeable areas and further reduce water detention and storage functions. The decrease of rainfall permeability leads to an increase of rainwater runoff, reducing the carrying capacity of the existing drainage canals and the chance of flooding is increased. In view of this, this study takes floods as the main research theme. Unlike previous studies of floods focusing on water conservancy projects, this study conducts correlation analyses between residents' attitudes toward flood prevention behavior and socio-economic backgrounds in different vulnerable areas, with a focus on age and residency duration.

\section{Literature Review}

\subsection{Risk perception and behavioral intention}

Risk is a "subjective" concept, often influenced by factors such as personal backgrounds, culture and social and economic status. Thus, it is difficult to have an "objective" concept of risk. Raaijmakers and his colleagues [12] define risk perception through the risk characteristics (awareness, anxiety and preparedness) related to the situation. Risk can be defined as the possibility of adverse consequences of exposure to the interactions of vulnerable elements under one or more social or natural hazards. Risk can also be expressed using the function of "risk $=$ hazard exposure $\mathrm{x}$ vulnerability" [13].

Scholars elucidate social conditions, disasters and risk perception [14]. For example, the poor tend to live in disaster-prone areas, especially in rural areas, because they do not have money or resources to live elsewhere [15]. In terms of existing disaster prevention risks, awareness of one aspect of emergency and disaster preparedness (e.g. firefighting regulation documents) is not necessarily related to increasing awareness and preparedness for other emergencies and disasters (e.g. earthquakes, storms and water pollution, etc.). Therefore, from the perspective of the ability to cope with risks, it is positive to include many stakeholders in disaster risk reduction practices.

\subsection{Sense of place, place identity, identify of place and place attachment}

Research on concepts such as place attachment, place identity and place meaning has developed rapidly in many homologous disciplines [16]. The relationship between identity of place and environmental risk perception is still unclear. However, it is clear that identity of place affects the importance of cognition and behavior, and also needs to be considered by different levels of risk. Place attachment, risk perception and responsive behavior can vary depending on the specific place in which they exist [17]. Other studies suggest that place attachment may in fact have negative mediating effects on subjective environmental risks and risk perceptions, as well as negative mediating effects on risk perception and responsive behavior.

Place attachment develops from environmental psychology, covering the individual's connection to home, and gradually extending to the neighborhood and local areas, etc., to express the individual's connection to a specific environment [18. Another relevant concept is the sense of place $[17,19]$, refers to the socialized relationship between the individual and the real world. Continuing these studies, place attachment is the emotional factor of a particular place of a person's place identity. Moreover, according to the "place-specific biases" similar to those referred to in the social/selfidentity process, place attachment may promote or hinder locally related behaviors [9] (De Dominicis et al., 2015). People seems to believe that the environment they live is safer than other environments (i.e. less exposed to risks). In fact, "place-specific biases" exist in numerous analyses [20] (Devine-Wright \& Batel, 2017).

\section{Research design}

\subsection{The study area}

This study used the NCDR's [11] disaster potential maps of seven disaster risks (flooding potential, streams with debris flow potential, active faults, rock falls, rock slides, dip slopes and falling rocks) to calculate natural vulnerability (NV) by calculating the percentage of the covered area. Social vulnerability (SV) was based on NCDR [11], using the Delphi Method to filter out 14 social vulnerability indicators, and then using the Analytic Hierarchy Process to calculate the weighting of these indicators. The average value was adopted as the baseline. The value of vulnerability greater than the average value was designated as the high vulnerability; whereas, the value less than the average value as the low vulnerability. Using this calculation framework, social vulnerability and natural vulnerability were divided into two categories of "high/low". Consequently, the integrated vulnerability of the four categories can be obtained: "high SV / high NV", "low SV / high NV", "low SV / low NV" "high SV / low NV" (Fig. 1).

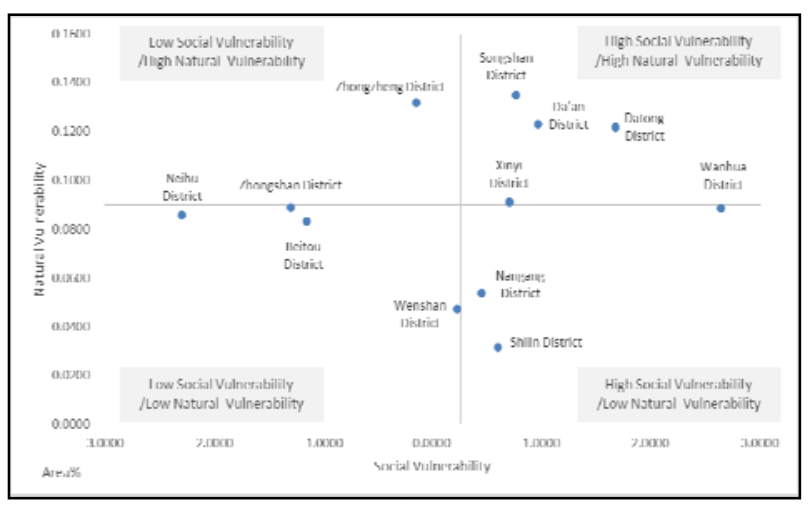

Figure 1. Integrated vulnerability of the 12 districts in Taipei 
The results show that districts with high social vulnerability and high natural vulnerability include Datong, Da'an, Wanhua, Xinyi, Songshan. These districts are areas with high potential impacts in the face of climate change, and have low disaster reduction, coping capacity and resilience building, which require urgent attention. For example, Datong District has the weak capacity for disaster reduction and preparedness, resulting in high vulnerability. Wanhua District is relatively inadequate in its resilience to disasters, due to the high vulnerability of shelter and the high vulnerability of the disadvantaged groups. The proportion of low-income households in Wanhua District is high, resulting in high vulnerability, and the low proportion of social welfare personnel in Datong District is high, resulting in high vulnerability.

The factors in the "exposure" dimension of social vulnerability include the size of industries and population. As a result, highly developed districts, due to high income and population, the loss will be large in the face of disasters, resulting in high vulnerability [21]. On the other hand, districts with low social vulnerability and low natural vulnerability, including Wenshan, Neihu, Beitou and Zhongshan, face the potential impact of climate change, and have higher disaster reduction, coping and resilience. Even so, in the face of the longterm climate change impact, there are still issues that must be dealt with.

Through the $600 \mathrm{~mm}$ flood potential map [11], more than half of Datong, Wanhua and Zhongshan districts are potential flooded areas. Therefore, Datong and Wanhua districts are selected as the study areas due to the high integrated vulnerability and more than half of the districts were flooded. Comparatively, Zhongshan and Wenshan districts were selected due to the low integrated vulnerabilities and more than half of the districts were flooded.

\subsection{Research method}

This study adopted a stratified random sampling method to select the respondent and 600 valid samples were completed. The questionnaire is mainly to explore respondents' flood prevention behavioral attitudes and socio-economic backgrounds. Therefore, based on the literature review, this study proposed preliminary questions to examine flood prevention behavioral attitudes. Whether or not the optimistic biases exist can be examined from the respondent's attitudes toward prevention behavior.

A random sample was implemented in the four districts in Taipei. Two interviewers were recruited to carry out the survey. In order to determine the validity and accuracy of each questionnaire, the interviewers take one-on-one visits to ensure that each questionnaire is complete and carefully filled out. Therefore, before the start of the survey, the researchers explained the intention of each topic one by one to the interviewers. A questionnaire standard operating procedure (SOP) was established for interviewers to follow when encountered difficulties. The SOP also explained the way of house- to-house visits, how to practice accurate exercises. After training and education, formal questionnaire surveys were carried out.

\section{Research Findings}

\subsection{Descriptive Statistics}

The age distribution of the samples was the largest in 2125 years of age, accounting for $18.2 \%$ of the total sample size, and the second was under 20 years of age, accounting for $13.7 \%$ of the total sample size. Male and female respondents were $45.2 \%$ and $54.8 \%$, respectively; in $2018,47.9 \%$ of males and $52.1 \%$ of females were in Datong, Zhongshan, Wanhua, Wenshan districts. Comparatively, the ratio of male to female respondents was roughly the same. The education level of the sample was distributed by the largest number of tertiary institutions, accounting for $62.5 \%$ of the total sample size, and the secondary to the high school (vocational) was $18.8 \%$ of the total sample number. The occupational distribution was the largest in the "student" category, accounting for $28.0 \%$ of the total sample, and "businesspersons" accounting for $20.2 \%$.

\subsection{Relationships between variables in different districts}

The different districts explored in this study refer to whether there is a difference between the two groups of "high social vulnerability / high natural vulnerability" and "low social vulnerability / low natural vulnerability". The variables analyzed include the age of the respondents, residency duration and attitudes toward flood prevention behavior.

\subsubsection{Correlation between age and attitudes toward prevention behavior}

Questions regarding attitudes toward flood prevention behavior in the questionnaire include: willing to participate in disaster prevention and rescue work (e.g., disaster prevention and rescue exercises); believing that the relevant contingency training is of great help to the safety of residential areas; concerned about flood risk information and flood situation in response to the increasing flood risk that Taiwan will face in the future; and storing spare supplies in the face of flood risk. Statistical analyses of the two variables (age and attitudes toward flood prevention behavior) show that there are significant correlations $(\mathrm{p}<0.05)$.

Under different spatial contexts, respondents' attitudes toward flood prevention behavior were related to respondents' age and different districts showed different results. De Dominicis et al. [9] (2015) indicate that the more people know about risk prevention, the more they will exhibit preventive behavior. However, "age" may be the main cause of differences in risk perception and risk anxiety. The insufficient absorption of risk knowledge, traditional myths, or differences in 
risk anxiety caused by the experience of the elderly as a result of their own disaster experiences may make "age" a factor in influencing attitudes toward preventive behavior. The correlation analyses between attitudes toward prevention behavior and age in Zhongshan and Wenshan districts (both with low integrated vulnerability) show moderate to low correlation relationships. It can be derived that "low natural vulnerability / low social vulnerability" represents less experience of natural disasters and higher social stability. As residents in these districts have more risk knowledge and have less relevant disaster experiences, "age" thus has a positive correlation with attitudes toward flood preventive behavior (Table 1).

Table 1. Correlation between respondents' age and attitudes toward flood prevention behavior in districts with different vulnerabilities.

\begin{tabular}{|c|c|c|c|c|}
\hline \multirow{2}{*}{$\begin{array}{c}\text { Vulnerabilities } \\
\text { Districts } \\
\text { Questions }\end{array}$} & \multicolumn{2}{|c|}{$\begin{array}{l}\text { High natural } \\
\text { vulnerability / } \\
\text { high social } \\
\text { vulnerability }\end{array}$} & \multicolumn{2}{|c|}{$\begin{array}{l}\text { Low natural } \\
\text { vulnerability / } \\
\text { low social } \\
\text { vulnerability }\end{array}$} \\
\hline & $\begin{array}{l}\text { Datong } \\
\text { District }\end{array}$ & $\begin{array}{l}\text { Wanhua } \\
\text { District }\end{array}$ & $\begin{array}{c}\text { Zhongshan } \\
\text { District }\end{array}$ & $\begin{array}{c}\text { Wenshan } \\
\text { District }\end{array}$ \\
\hline $\begin{array}{l}\text { Participation } \\
\text { in disaster } \\
\text { prevention and } \\
\text { rescue work } \\
\text { (e.g. disaster } \\
\text { prevention d } \\
\text { drills) has } \\
\text { helped my } \\
\text { area of } \\
\text { residence a lot }\end{array}$ & $\mathrm{x}$ & $\mathrm{x}$ & + & + \\
\hline $\begin{array}{l}\text { Taiwan will } \\
\text { face more and } \\
\text { more flood } \\
\text { risk in the } \\
\text { future }\end{array}$ & $\mathrm{x}$ & $\mathrm{x}$ & $\mathrm{x}$ & + \\
\hline $\begin{array}{c}\text { I will care } \\
\text { about flood } \\
\text { risk } \\
\text { information } \\
\text { and flood } \\
\text { situations } \\
\end{array}$ & $\mathrm{x}$ & $\mathrm{x}$ & + & + \\
\hline $\begin{array}{l}\text { I believe } \\
\text { storing spare } \\
\text { supplies is } \\
\text { redundant in } \\
\text { the face of } \\
\text { flood risk. }\end{array}$ & $\mathrm{x}$ & $\mathrm{x}$ & $\mathrm{x}$ & $\mathrm{x}$ \\
\hline
\end{tabular}

\subsubsection{Correlation between residency duration and attitudes toward prevention behavior}

Regarding the question (I will care about flood risk information and flood situations), Datong District and Wanhua District show low correlations, indicating respondents' attitudes toward prevention behavior and age have a low correlation in districts with high integrated vulnerability.

The results show that in cities with high integrated vulnerability, people with varying degrees of neighborhood attachment, in the case of high risk perception, high neighborhood attachment will reduce people's intention to adopt prevention behavior and actual prevention activities, which in turn will increase the risk when encountering actual disasters. Based on this observation, it can be concluded that residents in high integrated vulnerability districts (Datong District and Wanhua District), because of the long residency duration, experienced more natural disasters resulting in a high risk awareness, and further resulting in more positive attitudes toward prevention behavior. It can be inferred that residents in Datong District and Wanhua District have a low sense of place attachment.

Table 2. Correlation between respondents' residency duration and attitudes toward flood prevention behavior in districts with different vulnerabilities

\begin{tabular}{|c|c|c|c|c|}
\hline \multirow{2}{*}{$\begin{array}{c}\text { Vulnerabilities } \\
\text { Districts }\end{array}$} & \multicolumn{2}{|c|}{$\begin{array}{c}\text { High natural } \\
\text { vulnerability / } \\
\text { high social } \\
\text { vulnerability }\end{array}$} & \multicolumn{2}{|c|}{$\begin{array}{c}\text { Low natural } \\
\text { vulnerability / } \\
\text { low social } \\
\text { vulnerability }\end{array}$} \\
\cline { 2 - 5 } $\begin{array}{c}\text { Questions } \\
\text { Datong }\end{array}$ & $\begin{array}{c}\text { Wanhua } \\
\text { District }\end{array}$ & $\begin{array}{c}\text { District } \\
\text { Zhongshan } \\
\text { District }\end{array}$ & $\begin{array}{c}\text { Wenshan } \\
\text { District }\end{array}$ \\
\hline $\begin{array}{c}\text { Participation } \\
\text { in disaster } \\
\text { prevention and } \\
\text { rescue work } \\
\text { (e.g. disaster } \\
\text { prevention } \\
\text { drills) has } \\
\text { helped my } \\
\text { area of } \\
\text { residence a lot }\end{array}$ & $\mathrm{x}$ & $\mathrm{x}$ & $\mathrm{x}$ & $\mathrm{x}$ \\
\hline $\begin{array}{c}\text { Taiwan will } \\
\text { face more and } \\
\text { more flood } \\
\text { risk in the } \\
\text { future }\end{array}$ & $\mathrm{x}$ & $\mathrm{x}$ & $\mathrm{x}$ & $\mathrm{x}$ \\
\hline $\begin{array}{c}\text { I will care } \\
\text { about flood } \\
\text { risk } \\
\text { information } \\
\text { and flood } \\
\text { situations }\end{array}$ & + & + & $\mathrm{x}$ & $\mathrm{x}$ \\
\hline $\begin{array}{c}\text { I believe } \\
\text { storing spare } \\
\text { supplies is } \\
\text { redundant in } \\
\text { the face of } \\
\text { flood risk. }\end{array}$ & $\mathrm{x}$ & $\mathrm{x}$ & & \\
\hline
\end{tabular}

\section{Conclusions}

This study examined the relationship between attitudes toward prevention behavior and respondents' age and length of residence in different vulnerability districts in Taipei, Taiwan. De Dominicis et al. [9] indicated that the more people know about risk prevention, the more they will take preventive behavior. However, "age" may be the main cause of differences in risk perception and risk anxiety. The elderly's lack of absorption of risk knowledge, traditional myths, or differences in risk anxiety caused by the experience of the elderly as a 
result of their own disaster experiences may make "age" a factor in influencing attitudes toward prevention behavior. Comparatively, respondents in Zhongshan District and Wenshan District (low integrated vulnerabilities) show a low to moderate correlation between age and attitudes toward prevention behavior. It can be inferred that "low natural vulnerability / low social vulnerability" represents less experience in natural disasters and high social stability. Residents in these districts know more about disaster risks and have less relevant experiences, as a result, "age" is positively related to attitudes toward prevention behavior.

Four analyses of the correlation between attitudes toward prevention behaviour and residency duration were carried out in Datong and Wanhua districts of "high natural vulnerability / high social vulnerability." There is a low correlation for the question "I will care about flood risk information and flood situations". The other three questions showed no correlations. It is suggested that people in high natural vulnerability areas have experienced more natural disasters due to their long residency duration, and therefore have positive attitudes toward flood prevention behavior. Su et al. [22] suggested that in the process of risk perception, there are other "mediator variables" between disaster experiences and the individual's self-efficacy, making the past flood experiences relatively unimportant. Since the results of this study are different from the previous studies, "moderator variables" may exist and may include place attachment and place vulnerability.

\section{References}

1. W.W. Kellogg, R. Schware, Climate change and society: consequences of increasing atmospheric carbon dioxide (Routledge, 2019)

2. D. Eckstein, V. Künzel, L. Schäfer, M. Winges, Global Climate Risk Index 2020: Who Suffers Most from Extreme Weather Events? Weather-Related Loss Events in 2018 and 1999 to 2018 (Bonn: Germanwatch, 2020)

3. D. Eckstein, V. Künzel, L. Schäfer, Global Climate Risk Index 2018: Who Suffers Most From Extreme Weather Events? Weather-related Loss Events in 2016 and 1997 to 2016 (Bonn: Germanwatch, 2018)

4. D. Eckstein, M.L. Hutfils, M. Winges, Global Climate Risk Index 2019: Who Suffers Most From Extreme Weather Events? Weather-related Loss Events in 2017 and 1998 to 2017 (Bonn: Germanwatch, 2019)

5. T.T. Nguyen, H.H. Ngo, W. Guo, X.C. Wang, N. Ren, G. Li, J. Ding, H. Liang, Implementation of a specific urban water management - Sponge City. Sci. Total Environ. 652, 147-162 (2019)

6. A. Domeneghetti, F. Carisi, A. Castellarin, A. Brath, Evolution of flood risk over large areas: Quantitative assessment for the Po river. J. Hydrol. 527, 809-823 (2015)

7. W.R. White, Water in rivers: flooding, a contribution to the world water vision (UK: IAHR,
2000)

8. G. Cogut, N. Webster, R.W. Marans, J. Callerwaert, Links between sustainability-related awareness and behavior: the moderating role of engagement. Int. J. Sust. Higher Ed. 20, 7, 1240-1257 (2019)

9. S. De Dominicis, F. Fornara, U.G. Cancellieri, C. Twigger-Ross, M. Bonaiuto, We are at risk, and so what? place attachment, environmental risk perceptions and preventive coping behaviours. J. Environ. Psychol. 43, 66-78 (2015)

10. Lloyd's, Lloyd's City Risk Index (London: Lloyd's, 2020)

11. National Science and Technology Center for Disaster Reduction (https://dmap.ncdr.nat.gov.tw/, 2016).

12. R. Raaijmakers, J. Krywkow, A. van der Veen, Flood risk perceptions and spatial multi-criteria analysis: an exploratory research for hazard mitigation. Nat. Hazards 46, 3, 307-322 (2008)

13. M. Hagenlocher, F.G. Renaud, S. Haas, Z. Sebesvari, Vulnerability and risk of deltaic social-ecological systems exposed to multiple hazards. Sci. Total Environ. 631, 71-80 (2018)

14. M.M.G.T. De Silva, A. Kawasaki, Socioeconomic vulnerability to disaster risk: a case study of flood and drought impact in a rural Sri Lankan community. Ecol. Econ. 152, 131-140 (2018)

15. N.W. Chan, Choice and constraints in floodplain occupation: the influence of structural factors on residential location in Peninsular Malaysia. Disasters 19, 4, 287-307 (1995)

16. M. Lewicka, On the varieties of people's relationships with places: Hummon's typology revisited. Environ. Behav. 3, 676-709 (2011)

17. H. Casakin, B. Hernández, C. Ruiz, Place attachment and place identity in Israeli cities: the influence of city size. Cities 42, 224-230 (2015)

18. A. Gifford, A. Nilsson, Personal and social factors that influence pro-environmental concern and behaviour: A review. Int. J. Psychol. 49, 3 (2014)

19. P. Devine-Wright, Rethinking NIMBYism: the role of place attachment and place identity in explaining place-protective action. J. Community Appl. Soc. 19, 426-441 (2009)

20. P. Devine-Wright, S. Batel, My neighbourhood, my country or my planet? the influence of multiple place attachments and climate change concern on social acceptance of energy infrastructure. Global Environ. Chang. 47, 110-120 (2017)

21. IPCC, Climate Change 2014. Mitigation of Climate Change Summary for Policymakers and Technical Summary (2014)

22. Y. Su, X.P. Sun, F. Zhao, Trust and its effects on the public's perception of flood risk: a social science investigation of the middle and lower reaches of the Yangtze River, J. Flood Risk Manag. 10, 4, 487-498 (2017) 